\title{
Marian Szarmach*
}

\section{Sparta w kulturze polskiej (myśli przy lekturze)}

DOI: http://dx.doi.org/10.12775/LC.2018.058

latach 2014-2015 ukazały się w Warszawie w Wydawnictwie Naukowym Sub Lupa dwa tomy artykułów i wywiadów zatytułowane Sparta w kulturze polskiej, przygotowane pod redakcją związanych z Wydziałem „Artes Liberales” Uniwersytetu Warszawskiego i z Uniwersytetem Mikołaja Kopernika Małgorzaty Borowskiej, Marii Kalinowskiej, Jerzego Speiny, Katarzyny Tomaszuk i Damiana Kai. Oba te tomy przypomniały mi moje sześćdziesięcioletnie kontakty z antykiem i podróże, jakie odbyłem po świecie greckim.

Tom pierwszy rozpoczynają i kończą dwie rozmowy z profesorami historii starożytnej i filologii klasycznej. Uznany badacz dziejów Sparty, Ryszard Kulesza, mówiąc o „dwu Spartach”, silnie podkreśla, że obraz przekazany przez Plutarcha, Pauzaniasza i Pliniusza, a więc autorów z I/II wieku, stworzył mit Sparty, w której wszyscy byli równi, a młodych, dzielnych Spartan nie wychowywano, lecz tresowano, by służyli potędze swego państwa (Kaniecki 2014a). Dodam, że Eurypides, świadek wojny peloponeskiej (431-404 przed Chr.), w tragedii Andromacha powstałej około 425 roku przed Chr. tak mówi:

Mieszkańcy Sparty, podstępni doradcy, ze wszystkich ludzi jesteście najgorsi!

Mistrzowie kłamstwa, zdradliwi w pomysłach, [...] czyż wciąż nie mówicie językiem sprzecznym z tym, co macie w sercu? (w. 445 i in., przekład R. Chodkowskiego) (Eurypides 2017: s. 427).

Słowa te przytacza włoski znawca literatury greckiej i tłumacz Powiedzeń spartańskich Plutarcha Dario del Corno w obszernym wstępie do tego przekładu, dodając jeszcze Platona i Ksenofonta jako głównych idealizatorów Sparty, w której nie było miejsca na „przygodę

* Emerytowany profesor Uniwersytetu Mikołaja Kopernika w Toruniu. Zainteresowania badawcze: tragedia grecka, cesarska literatura grecko-rzymska, autorzy Drugiej Sofistyki i wczesnochrześcijańscy.

E-mail: marszar@umk.pl. 
myślenia i piękno sztuki” (Plutarco 1996: 26). Wymienione pismo Plutarcha przyswoiła ostatnio kulturze polskiej Katarzyna Jażdżewska, opatrując je wstępem i obszernym komentarzem (Plutarch 2006: 15-28).

W drugiej, wielowątkowej rozmowie Sparta Polonorum, paradoksy ciagłości i nieciagłości Jerzy Axer akcentuje kanoniczny dla polskiej recepcji Sparty Grób Agamemnona Juliusza Słowackiego, który „piętnuje przemianę duchową szlachcica polskiego w Leonidasa” odnoszącego nieustannie „Zwycięskie klęski” (Kaniecki 2014: 491). Ważny jest więc postulat, by Polacy wertowali „za dnia i w nocy” głównych historyków antycznych: Tukidydesa i Tacyta, od których nauczą się, jak postępować rozumnie. W najgorszych miesiącach stanu wojennego ich lekturę zalecała mi profesor Zofia Abramowiczówna.

W Grecji byłem po raz pierwszy w 1976 roku, już po doktoracie, z wycieczką Orbisu, co było wówczas jedyną możliwością dla takich jak ja. Trasę tę przemierzał w tym samym czasie Mieczysław Jastrun, a owocem jego wyprawy jest zbiór esejów Podróż do Grecji (1978). Jednym z pierwszych przystanków były Termopile, gdzie trzystu Spartan, broniąc się pod wodzą Leonidasa przed Persami, poniosło w roku 480 przed Chr. śmierć. Upamiętnia to wystawiony tam w roku 1955 pomnik przedstawiający Leonidasa w hełmie hoplity na głowie. Starożytny jego posąg znajduje się w Muzeum Narodowym w Atenach. Nieopodal umieszczono płytę ze sławnym epigramem prawdopodobnie poety Simonidesa, stworzonym dla uczczenia poległych:

Gościu, oznajmij Lacedemończykom, że w boju poległszy -

Tu spoczywamy po wiek, wiernie słuchając ich praw.

(przekład S. Hammera) (Herodot 2002: 449)

Jastrun pisze ze smutkiem, że „w Polsce pamięta się o tej bohaterskiej walce garstki w dużym stopniu dzięki strofom z Grobu Agamemnona. Co prawda nie wszyscy, zwłaszcza młodzi, znają ten wiersz. Tak jak w ogóle ich wiedza z zakresu historii ojczystej i innych narodów przedstawia wiele do życzenia” (Jastrun 1978: 9-10). Kulesza w artykule Termopile $w$ Polsce i na świecie, próba rekonesansu przytacza, jak bezmyślnie z tą pełną chwały klęską Greków porównuje się dziś różne śmieszne niepowodzenia, co często brzmi już nie banalnie, ale kompromituje (Kulesza 2014: 384). W 2011 roku w jednej z gazet porażkę trzystu żołnierzy egzaminowanych na stopień kaprala porównano do losu bohaterskich Spartan w Termopilach.

Z artykułów umieszczonych w tym tomie przywołam jeszcze teksty Marii Kalinowskiej, Ewy Owczarz i Jerzego Speiny. Kalinowska, pisząc o Sparcie w dialogach greckich Słowackiego i Stanisława Wyspiańskiego, zwróciła uwagę, że Słowacki łączy ofiarę Chrystusa z bohaterskim Leonidasem, który ma być zapowiedzią Zbawiciela (Kalinowska 2014: 204). Klechda o Leonidasie Elizy Orzeszkowej jest przedmiotem studium Owczarz, wykazującej, że w powstałym po powstaniu styczniowym zbiorze nowel Gloria victis Romuald Traugutt został przedstawiony jako Leonidas. Jego wojownicy są „dobrowolnymi ofiarami wysokich ołtarzy" (Owczarz 2014: 262), a on sam staje się Tyrteuszem. Orzeszkowa gloryfikuje Spartę piękną duchem i ciałem. Obszerny artykuł Speiny Reminiscencje spartańskie w poezji polskiej XX w. zawiera przegląd okolicznościowej poezji patriotycznej z lat 1914-1918 i zwraca uwagę, że wizerunek Sparty, Tyrteusza i Leonidasa wpłynął na teksty związane z wydarzeniami z tego czasu (Speina 2014: 273). Dochodzące wówczas do głosu 
słowa poetów, sławiące moralne piękno heroicznego czynu, spotkały się z krytyką autorów związanych z krakowskim „Życiem”, którzy widzieli w tych tonach fałszywy blask nowej romantycznej legendy. Przeciwstawił się temu stanowczo Henryk Elzenberg, twierdząc, że są to rzeczy rdzennie helleńskie, czego przykładem jest Tyrteusz, poeta prawdopodobnie spartański z VII wieku przed Chr., mówiący:

Rzecz to piękna zaprawdę, gdy krocząc w pierwszym szeregu, Ginie człowiek odważny, walcząc w obronie ojczyzny

(przekład W. Appela). (Danielewicz 1996: 432)

Nie bez znaczenia jest, że Elzenberg zaciągnął się w roku 1914 do Legionów i walczył w kampanii polsko-bolszewickiej.

Z powodów osobistych nie mogę pominąć artykułu Grażyny Halkiewicz-Sojak Sparta Zbigniewa Herberta, gdzie Lacedemon został przedstawiony jako państwo kontrolujące wszystko według ideologicznych założeń, w którym edukację organizuje ślepa siła. Pod koniec autorka pisze o VII Lwowskim Gimnazjum, gdzie postawy uczniów, w tym i Herberta, kształtował „łacinnik, przed którym drżeli uczniowie” (Halkiewicz-Sojak 2014: 355). Taką nauczycielkę łaciny, studentkę Tadeusza Zielińskiego, miałem i ja w latach pięćdziesiątych w szkole w Kwidzynie. Dziś nie ma już takich, bo z naszych szkół łacina została, mówiąc za Horacym, furca expulsa - wypędzona widłami, chociaż ci, którzy polską oświatą władają, ciągle mówią o antycznych korzeniach naszej kultury.

Alicja i Przemysław Kordosowie piszą o polskich podróżnikach po Sparcie (Kordos, Kordos 2014). Jedną z tamtejszych atrakcji turystycznych, wymienioną już w II wieku przez Pauzaniasza, autora Przewodnika po Grecji, była wzniesiona poza miastem świątynia Artemidy z przydomkiem Orthia, czyli Wyprostowanej, z VIII wieku przed Chr. Kiedy tam byłem, przeraziły mnie watahy wałęsających się wszędzie bezdomnych psów. W świątyni znajdował się w starożytności drewniany posąg bogini, który Orestes z Ifigenią mieli wykraść z Taurydy. W sanktuarium tym odbywały się ceremonie sakralnej chłosty, wymierzanej młodym Spartanom jako próba ich wytrzymałości. Smagani chłopcy współzawodniczyli, który dłużej wytrzyma. Cyceron (Tusc. II 34; Cicero 1904: 340) przekazuje, że podczas tego obrzędu multus e visceribus sanguis exeat - „z ciała płynie obficie krew” (Cyceron 1961: 568). Dla żądnych oglądania tego barbarzyńskiego obrazu wzniesiono w czasach rzymskich nawet małą widownię, której resztki, tak jak fundamenty świątyni, się zachowały.

Tom drugi Sparty w kulturze polskiej, zatytułowany Przekroje, syntezy i konteksty, a wydany w roku 2015 pod redakcją Małgorzaty Borowskiej, Damiana Kai, Marii Kalinowskiej i Jerzego Speiny, otwiera rozmowa z Aliną Nowicką-Jeżową na temat kształtowania się obrazu Sparty w literaturze polskiej przed XIX wiekiem. W dobie odrodzenia wątki spartańskie pojawiały się u nas rzadko. Wysokim uznaniem cieszyły się Powiedzenia spartańskie Plutarcha, do których renesansowi autorzy chętnie się odwołują. W XVII i XVIII wieku zaczyna dominować spartańska idea honorowej śmierci w walce, połączona $\mathrm{z}$ hierofanią Termopil, co utrzymuje się w poezji porozbiorowej. W literaturze XVII wieku dochodzi też do połączenia sacrum ojczyźnianego i religijnego, kiedy Pan Bóg przyjmuje wprost z pola walki wszystkich poległych, skąd niedaleko do żołnierzy idących „do nieba czwórkami” (Kaniecki 2015: 20). Kojarzone z Atenami nauka i sztuka nie znajdują uznania u obywatela szlachcica, dla którego święta prostota staje się prostactwem (ibid.: 21). 
Elżbieta Wesołowska zajęła się Helena $w$ tradycji antycznej $i$ literaturze polskiej (Wesołowska 2015). Spartanka Helena pojawia się już w VI księdze Iliady, gdzie zachwycają się jej urodą starcy trojańscy. W „retorycznej igraszce”, jaką jest jej pochwała ułożona przez Gorgiasza (V wiek przed Chr.) - tekście studiowanym jeśli nie w oryginale, to w przekładzie przez wszystkich zajmujących się antyczną wymową - sofista przekonuje, że chociaż porzuciła męża Menelaosa dla Trojanina Parysa, jest niewinna, bo mogła ulec przemocy, sile miłości, namowie czy boskiej konieczności. Nieco młodszy od Gorgiasza retor Isokrates w swej Pochwale Heleny uważa, że jej uroda czyni ją wartą miłości. Szkoda, że autorka nie przywołała tu tragedii Eurypidesa Helena (412 przed Chr.), w której przebywającej w Egipcie bohaterce Chór zarzuca (w. 1353 i n.):

Co się nie godzi i co bezbożne,

na to ważyłaś się w swoim domu [...].

Powściągnij teraz tę dumę

przesadną, przez którą

pięknością się tylko szczyciłaś.

(przekład J. Łanowskiego) (Eurypides 2007: 83)

Zbezczeszczenie świętych obrzędów może być aluzją do słynnego z urody Alkibiadesa, który, oskarżony w roku 415 przed Chr. o sprofanowanie misteriów eleuzyńskich, uciekł do Sparty, co pociągnęło za sobą prawdopodobnie klęskę wyprawy sycylijskiej w wojnie peloponeskiej. Plutarch w Żywocie Alkibiadesa (23) przekazuje, że tam uwiódł żonę króla Agisa Timaję, która „[...] poczęła z niego i nie wypierała się, że to z Alkibiadesa. Urodziła syna i na zewnątrz nazwała go Leotychidasem, ale w domu miał imię Alkibiadesa, szeptane przez matkę do ucha przyjaciółkom i służącym. Taka miłość do niego opanowała tę kobietę. [...] Dlatego Leotychidas nie doszedł potem do godności królewskiej” (Plutarch 1996: 84).

Marta Dąbrowska w artykule Tropy spartańskie w „esejach greckich” Stanisława Vincenza pisze, że ten emigracyjny twórca, sięgający do greckiego dziedzictwa, zajmował się również Spartą. W jej militarnej potędze widział zagrożenie dla niej samej. Szaleństwo wojny peloponeskiej dotknęło tak ją, jak Ateny. Obie te greckie poleis „zbyt późno przekonały się, że Hellenowie nie powinni niszczyć Hellenów” (Dąbrowska 2015: 225) i że nie mogą hołdować spartańskiemu „zwyrodnieniu ksenofobii”. Stosunkiem Vincenza do antyku zajmuje się ostatnio Jacek Hajduk, filolog klasyczny i polonista z UJ, autor książek o antycznych ścieżkach Stanisława Stempowskiego (2016) i Gustawa Herlinga-Grudzińskiego (2017). Oby i ta trzecia była tak dobra jak poprzednie!

Żyjący w II wieku i piszący doskonale po grecku Rzymianin Elian z Praeneste w Opowiastkach rozmaitych (XII 50) napisal, że Spartanie „nie znali służby Muzom [...] nie interesowało ich zbytnio wykształcenie" (Elian 2005: 229]. Wypada na zakończenie przytoczyć refleksję Ignacego Wieniewskiego, adiutanta gen. Hallera, a zarazem tłumacza Iliady i Eneidy, z jednego z jego esejów powstałych po podróży po Grecji:

Idealny obraz demokracji ateńskiej nakreślony przez Tukidydesa może nasunąć sarkastyczną refleksję. Historyk grecki przeciwstawił tę demokrację totalitarnej Sparcie, z którą toczyła wojnę. I któż zwyciężył? Właśnie Sparta. Ostatecznie jednak potęga Sparty trwała krócej, niż potęga Aten i ich imperium. A cóż dopiero mówić o dorobku kulturalnym! Pod tym względem plon starożytnego państwa totalitarnego jest zawstydzająco ubogi. Tukidydes jest ciągle 
cennym sprzymierzeńcem $\mathrm{w}$ walce o odkłamywanie tego pojęcia demokracji (Wieniewski 1980: 32).

\section{Bibliografia}

Dąbrowska, Marta 2015. Tropy spartańskie w „esejach greckich” Stanisława Vincenza. Notatki z lektu$r y$. W: Małgorzata Borowska, Damian Kaja, Maria Kalinowska, Jerzy Speina (red.). Sparta w kulturze polskiej. Cz. 2: Przekroje, syntezy, konteksty. Warszawa: Wydawnictwo Naukowe Sub Lupa.

Cicero, Marcus Tullius 1904. Scripta quae mansuerunt omnia. Pars IV, vol. I. C. F. W. Mueller (red.). Lipsiae: In Aedibus B. G. Teubneri.

Cyceron, Marcus Tullius 1961. Księgi akademickie. O najwyższym dobru i złu. Paradoksy stoików. Rozmowy tuskulańskie. Przełożył W. Kornatowski, J. Śmigaj, komentarzem opatrzył K. Leśniak, Warszawa: Państwowe Wydawnictwo Naukowe.

Danielewicz, Jerzy (red.). Liryka starożytnej Grecji. Warszawa-Poznań: Wydawnictwo Naukowe PWN.

Elian, Klaudiusz 2005. Opowiastki rozmaite. Listy wieśniaków. Przełożyła i wstępem poprzedziła M. Borowska, przypisami opatrzyła M. Borowska przy współpracy A. Masłowskiej-Nowak. Warszawa: Prószyński i S-ka.

Eurypides 2007. Helena, Fenicjanki, Orestes. Przełożył, wstępem i przypisami opatrzył Jerzy Łanowski, przekład przejrzała Janina Ławińska-Tyszkowska. Warszawa: Prószyński i S-ka.

- 2017. Tragedie. T. 1. Przełożył, wstępem i przypisami opatrzył Robert R. Chodkowski. Lublin: Towarzystwo Naukowe Katolickiego Uniwersytetu Lubelskiego Jana Pawła II.

Halkiewicz-Sojak, Grażyna 2014. Sparta Zbigniewa Herberta. W: Małgorzata Borowska, Maria Kalinowska, Jerzy Speina, Katarzyna Tomaszuk (red.). Sparta w kulturze polskiej. Cz. 1: Model recepcji, spojrzenie europejskie, konteksty greckie. Warszawa: Wydawnictwo Naukowe Sub Lupa.

Herodot 2002. Dzieje. Z języka greckiego przełożył i opracował Seweryn Hammer. Warszawa: Czytelnik.

Jastrun, Mieczysław 1978. Podróż do Grecji. Kraków: Wydawnictwo Literackie.

Kalinowska, Maria 2014. Sparta w dialogach "greckich” dziet Juliusza Stowackiego i Stanistawa Wyspiańskiego (próba sformutowania pytań). W: Małgorzata Borowska, Maria Kalinowska, Jerzy Speina, Katarzyna Tomaszuk (red.). Sparta w kulturze polskiej. Cz. 1: Model recepcji, spojrzenie europejskie, konteksty greckie. Warszawa: Wydawnictwo Naukowe Sub Lupa.

Kaniecki, Przemysław 2014a. Dwie Sparty. Rozmowa z Ryszardem Kulesza. W: Małgorzata Borowska, Maria Kalinowska, Jerzy Speina, Katarzyna Tomaszuk (red.). Sparta w kulturze polskiej. Cz. 1: Model recepcji, spojrzenie europejskie, konteksty greckie. Warszawa: Wydawnictwo Naukowe Sub Lupa.

- 2014b. Sparta Polonorum. Paradoksy ciagtości i nieciagtości. Rozmowa z Jerzym Axerem. W: Małgorzata Borowska, Maria Kalinowska, Jerzy Speina, Katarzyna Tomaszuk (red.). Sparta w kulturze polskiej. Cz. 1: Model recepcji, spojrzenie europejskie, konteksty greckie. Warszawa: Wydawnictwo Naukowe Sub Lupa.

- 2015. Przed wiekiem XIX. Ksztaltowanie się stereotypu Sparty w literaturze staropolskiej. Rozmowa $z$ Alina Nowicka-Jeżowa. W: Małgorzata Borowska, Damian Kaja, Maria Kalinowska, Jerzy Speina (red.). Sparta $w$ kulturze polskiej. Cz. 2: Przekroje, syntezy, konteksty. Warszawa: Wydawnictwo Naukowe Sub Lupa.

Kordos, Alicja, Kordos, Przemysław 2014. Polscy podróżnicy w Sparcie. W: Małgorzata Borowska, Maria Kalinowska, Jerzy Speina, Katarzyna Tomaszuk (red.). Sparta w kulturze polskiej. 
Cz. 1: Model recepcji, spojrzenie europejskie, konteksty greckie. Warszawa: Wydawnictwo Naukowe Sub Lupa.

Kulesza, Ryszard 2014. Termopile - w Polsce i na świecie. Próba rekonesansu. W: Małgorzata Borowska, Maria Kalinowska, Jerzy Speina, Katarzyna Tomaszuk (red.). Sparta w kulturze polskiej. Cz. 1: Model recepcji, spojrzenie europejskie, konteksty greckie. Warszawa: Wydawnictwo Naukowe Sub Lupa.

Owczarz, Ewa 2014. Elizy Orzeszkowej klechda o Leonidasie („Gloria victis” na tle utworów pisarki o tematyce antycznej). W: Małgorzata Borowska, Maria Kalinowska, Jerzy Speina, Katarzyna Tomaszuk (red.). Sparta w kulturze polskiej. Cz. 1: Model recepcji, spojrzenie europejskie, konteksty greckie. Warszawa: Wydawnictwo Naukowe Sub Lupa.

Plutarch 1996. Żywoty sławnych mężów ( $z$ żywotów równolegtych). Z języka greckiego przełożył i komentarzem opatrzył M. Brożek. Wrocław: Zakład Narodowy im. Ossolińskich.

- 2006. Powiedzenia królów i wodzów, powiedzenia spartańskie. Tłum., wstępem i objaśnieniami opatrzyła Katarzyna Jażdżewska. Warszawa: Prószyński i S-ka.

Plutarco 1996. Le virtù di Sparta. A cura di Dario Del Corno, traduzione dal greco antico e note di Giuseppe Zanetto. Milano: Adelphi.

Speina, Jerzy. 2014. Reminescencje spartańskie w poezji polskiej XX w. W: Małgorzata Borowska, Maria Kalinowska, Jerzy Speina, Katarzyna Tomaszuk (red.). Sparta w kulturze polskiej. Cz. 1: Model recepcji, spojrzenie europejskie, konteksty greckie. Warszawa: Wydawnictwo Naukowe Sub Lupa.

Wesołowska, Elżbieta 2015. Helena w tradycji antycznej i literaturze polskiej. W: Małgorzata Borowska, Damian Kaja, Maria Kalinowska, Jerzy Speina (red.) 2015, Sparta w kulturze polskiej. Cz. 2: Przekroje, syntezy, konteksty. Warszawa: Wydawnictwo Naukowe Sub Lupa.

Wieniewski, Ignacy 1980. Pisma wybrane. Londyn: Oficyna Poetów i Malarzy. 